This item was submitted to Loughborough's Research Repository by the author.

Items in Figshare are protected by copyright, with all rights reserved, unless otherwise indicated.

\title{
Peroneal reaction time delayed but dynamic single-legged stability retained in collegiate footballers during a simulated prolonged football protocol
}

\section{PLEASE CITE THE PUBLISHED VERSION}

https://doi.org/10.1080/15438627.2020.1857251

\section{PUBLISHER}

Taylor \& Francis (Routledge)

\section{VERSION}

AM (Accepted Manuscript)

\section{PUBLISHER STATEMENT}

This is an Accepted Manuscript of an article published by Taylor \& Francis in Research in Sports Medicine on 9 Dec 2020, available online: http://www.tandfonline.com/10.1080/15438627.2020.1857251.

\section{LICENCE}

CC BY-NC-ND 4.0

\section{REPOSITORY RECORD}

Huang, Zhanyu, Wei Shan, Junyuan Ding, Wei Sun, and Daniel Fong. 2020. "Peroneal Reaction Time Delayed but Dynamic Single-legged Stability Retained in Collegiate Footballers During a Simulated Prolonged Football Protocol". Loughborough University. https://hdl.handle.net/2134/13285844.v1. 


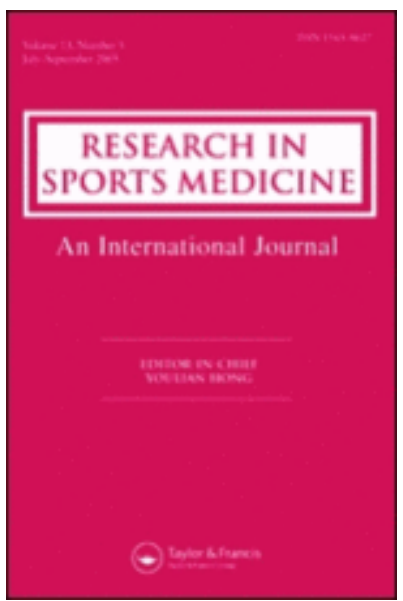

Peroneal reaction time delayed but dynamic single-legged stability retained in collegiate footballers during a simulated prolonged football protocol

\begin{tabular}{|r|l|}
\hline Journal: & Research in Sports Medicine \\
\hline Manuscript ID & GSPM-2020-0392.R2 \\
\hline Manuscript Type: & Original Research \\
\hline Keywords: & $\begin{array}{l}\text { ankle sprain, sensorimotor control, ligamentous sprain, soccer, ankle } \\
\text { injuries }\end{array}$ \\
\hline \multicolumn{2}{|l}{} \\
\hline
\end{tabular}

\section{SCHOLARONE \\ Manuscripts}




\title{
Peroneal reaction time delayed but dynamic single-legged stability retained in collegiate footballers during a simulated prolonged football protocol
}

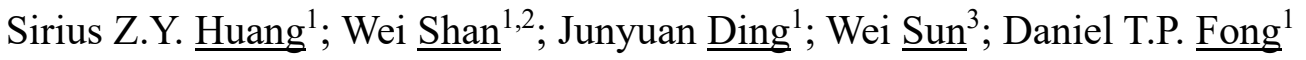 \\ ${ }^{1}$ National Centre for Sport and Exercise Medicine, School of Sport, Exercise and Health \\ Sciences, Loughborough University, Loughborough, UK \\ ${ }^{2}$ China Institute of Sport and Health Science, Beijing Sport University, Beijing, China \\ ${ }^{3}$ Shandong Sport University, Jinan, China
}

Correspondence author:

Dr Daniel T.P. Fong

ORCID: 0000-0001-7314-189X

National Centre for Sport and Exercise Medicine,

School of Sport, Exercise and Health Sciences,

Loughborough University,

Loughborough, UK, LE11 3TU

d.t.fong@1boro.ac.uk

Acknowledgement: The authors of this paper would like to thank MSc. Jiu Pan, BSc. Heng Zhang, BSc. Spencer Sun from Loughborough University for the assistance in experiments.

Contributors: SH was responsible for the concept and design of the study. SH, Shan and JD conducted the recruitment, design of equipment and date collection. SH, JD and DF conducted the data analysis and SH and DF interpreted the date for the findings. SH wrote the first draft and critically revised by Sun, Shan and DF. 
1 ABSTRACT

2 Delayed peroneal reaction time and impaired single-legged dynamic stability were risk 3 factors of lateral ankle sprain (LAS), yet no study explored the change of them during a 4 football match. The aim is to explore the change of peroneal reaction time and single-legged 5 dynamic stability during a football simulation protocol. Twelve collegiate football players 6 voluntarily completed a 105-minute football match simulation protocol in which peroneal 7 reaction time, root mean square of mediolateral ground reaction force in first $0.4 \mathrm{~s}$ (RMS ML 8 0.4), and the mean mediolateral ground reaction force in the late stage (late dynamic 9 MLGRF), were measured for both legs at 15-minute intervals during the protocol. Peroneal 10 reaction time was tested using an electromyography (EMG) system. The ground reaction force variables were measured from GRF data after a single-legged drop-jump landing. Repeated measures one-way MANOVA was conducted to evaluate variables over time and leg dominance. Statistical significance was set at $p<0.05$ level. Peroneal reaction time significantly increased for both legs at 45 minutes and after 60 minutes. RMS ML 0.4 of both legs and late dynamic MLGRF for dominant leg remained unchanged throughout the protocol and late dynamic MLGRF for non-dominant leg significantly reduced at the 90th minute.

Key Words: ankle sprain, sensorimotor control, ligamentous sprain, soccer, sports medicine, ankle injuries, biomechanics 
What are the findings?

$>$ Peroneal reaction time significantly increased, while the dynamic single-legged stability remained unchanged during prolonged football match simulation.

$>$ The results defied the previous hypothesis that the increased peroneal reaction time might result in the increased risk of lateral ankle sprain in the late phase of football match.

How might it impact on clinical practice in the future?

$>\quad$ There is a need to identify the principles and mechanisms underpinning in the late phase of a football match, in addition to impaired neuromuscular function.

$>$ Research is also required to test the change of peroneal reaction time in professional players and in real match setting.

\section{INTRODUCTION}

Lateral ankle sprain (LAS) is one of the most common lower-body musculoskeletal injuries in all performance level of football(Ekstrand et al., 2019) with injury rate as high as 4.4 incidences per 1000 hours of match exposure (Ekstrand \& Tropp, 1990; Waldén et al., 2013). The occurrence of LAS caused heavy socioeconomic loss to professional players and the club(Ekstrand, 2013) and predisposed athletes to ankle instability(Anandacoomarasamy \& Barnsley, 2005) and potentially higher risk of recurrent ankle sprain(Yeung et al., 1994).

More than two-thirds of LAS in football occurred during a high-performance football match(Hawkins et al., 2001) and more than $50 \%$ of LAS happened in the last 15 minutes of each half of the match, indicating that prolonged football participation might play an important role in the mechanisms of the LAS(Cloke et al., 2009; Fousekis et al., 2012), Numerous risk factors of LAS have been identified, including delayed peroneal muscles reaction time(Hoch \& McKeon, 2014) and impaired dynamic single-legged stability(Fransz et al., 2018). These two risk factors could all lead to mismanagement of the centre of mass during rapid landing, sprinting, and turning maneuvers, which were identified as the primary cause for non-contact LAS in football(Andersen et al., 2004).

The time latency required for peroneal muscles to react against a sudden inversion perturbation is termed as peroneal reaction time(Thain et al., 2016). Peroneal reaction time in healthy ankle ranged from 55-85ms(Dufek \& Bates, 1991; Eechaute et al., 2009; Fernandes et al., 2000; Hoch \& McKeon, 2014; L. Konradsen \& Bohsen Ravn, 1991; Lars Konradsen et al., 1998; Ty Hopkins et al., 2007). Peroneal reaction time has been recognised as an indicator of the involuntary ankle sensorimotor control in unexpected ankle inversion, as it reflects the capability of involuntary, close-loop reflex of the neuromuscular control of the ankle joint (Hoch \& McKeon, 2014). The reaction of peroneal muscles during a rapid and 
forceful ankle inversion was proposed to serve as a neuromuscular defense of the lateral tissue of the joint from injury(D. T. Fong et al., 2009). Thus, elongated or delayed peroneal reaction time would postpone the reaction of the peroneal muscles, and leading to augmented the vulnerability of the ankle joint to injury(D. T. Fong et al., 2009). Clinically, peroneal reaction time has been used as a measurement to assess the involuntary neuromuscular reactive function among patients with chronic ankle instability and showed moderate delayed peroneal reaction time compared to healthy subject(Eechaute et al., 2007; Hoch \& McKeon, 2014; Löfvenberg et al., 1995; Shima et al., 2005)

70

71

72

On the other hand, dynamic single-legged stability, especially in the mediolateral direction, after landing was recognised as an important voluntary sensorimotor control, as well as a representation of the whole-body sensorimotor function in football performance(Witchalls et al., 2013). Poor dynamic stability indicates more endeavour being required to maintain the position of the ankle joint and posture, leading to higher chances of unexpected ankle inversion perturbation(Fransz et al., 2018). Fransz et al have identified that two valid and reliable risk factors, reflected by ground reaction force (GRF), among dynamic single-legged stability variables which showed moderate to the strong association of occurrence of LAS in high-performance footballers: the root mean square of mediolateral ground reaction force in first $0.4 \mathrm{~s}$ (RMS ML 0.4) and the mean mediolateral ground reaction force in the late stage (3-5s after landing, late dynamic MLGRF) after single-legged landing(Fransz et al., 2014). The former represents the spontaneous reflection of mediolateral force absorption and control and the latter indicates the overall dynamic stability on one leg after landing(Fransz et al., 2016).

However, the change of the peroneal reaction time and single-legged dynamic stability control of the ankle joint during a football match has yet to be explored. The aims were to explore the influence of a prolonged football simulation protocol on dynamic single-legged stability and peroneal reaction time, to provide stakeholders in high-performance football with valuable information regarding the susceptibility of LAS during football match participation. The hypothesises were (1) peroneal reaction time would increase and (2) RMS ML 0.4 and late dynamic MLGRF would increase as the protocol proceeds.

\section{METHOD}

\section{Participants}

The sample size was estimated according to previous studies which recorded the delayed peroneal reaction time from $40.76 \pm 10.90$ to $47.98 \pm 7.32$ for the dominant leg and $40.52 \pm 2.95$ to $45.74 \pm 4.00$ for the non-dominant $\operatorname{leg}(\mathrm{D}$. T. P. Fong et al., 2020) and the change of RMS ML 0.4 of $4.22 \pm 0.86$ percent of body weight(Fransz et al., 2018), respectively. The statistical power was set at 0.80 and the level of significance at 0.05 . The 
estimated sample sizes were 6 and 12, respectively. Additionally, previous literature suggested that no gender difference existed in the change of peroneal reaction time and single-legged balance control(Benesch et al., 2000). 12 healthy collegiate footballers (11 males and 1 female, mean \pm standard deviation: age $23.0 \pm 2.5$ years; height $168.0 \pm 6.0 \mathrm{~cm}$; weight $67.8 \pm 8.2 \mathrm{~kg}$, training age $6.3 \pm 4.3$ years). The inclusion criteria were the participants should be 1) aged between 18 to 35,2 ) free from musculoskeletal conditions that were not allowed for vigorous exercise, 3 ) no previous severe ankle injury history that could affect the functional movement of the ankle, and 4) having received at least 3 years of systematic football training having regular football participation (minimum of once a week in recent three months). All participants finished the Health Screen Questionnaire and were clear for the study. Potential risks of the experiment had been verbally and formally explained to the participants and informed consent was signed by every participant before partaking in the study.

\section{Foot dominance}

All of the participants were asked to specify the dominance foot, which is defined as the foot they preferred to kick the football.

\section{Prolonged football match simulation protocol}

Participants were asked to complete a modified Loughborough Intermittent Shuttle Test Protocol (LIST)(Nicholas et al., 2000), to simulate football-specific fatigue (Figure 1). The LIST consisted of two 45-minute-halves and a 15-minute-half-time break. Each half was divided into three 15-minute blocks, in which participants were asked to perform rounds of football-specific running drills repetitively until 15 minutes. A round of drills consisted of 60-meter-walk, 20-meter-sprint, and an in-sole ball passing, followed by 60-meter-jogging, 60-meter-sprint, and an insole ball passing to simulate actual football match technical and physical endeavour.

\section{Testing methods}

A set of tests of peroneal muscles reaction and postural stability, including 2 trials of singlelegged drop-jump landing (SLDJ) per foot and 2 trials of ankle trapdoor simulation per foot, was conducted before, every 15-minute interval of the LIST and immediately after the LIST, in a total of 8 sets of tests being conducted per participant. Participants were asked to remove their boots before the tests and performed the tests wearing socks(Fransz et al., 2018). Peroneal longus muscle belly was identified by palpation during ankle eversion. The skin area of both sides of peroneal longus muscles was carefully shaved and scrubbed with sandpaper to remove dead skin.

The participants were asked to perform two single-legged drop-jump landings by jumping 
from an aerobic step to a force plate (Model 9287CA, Kistler Instruments Ltd, UK). The

141

142

143

144

145

146

147

148

149

150

151

152

153

154

155

156

157

158

159

160

161

162

163

164

165

166

167

168

169

170

171

172

173

174

175

176

177

178

Aerobic Step was set at $20-\mathrm{cm}$ of height and placed 5-cm behind the force plate(Fransz et al., 2018). The participants were instructed to stand on the aerobic step and remained still before being instructed to jump on 2 feet and to land on the testing foot on the force plate (Figure 2). Participants should stabilise their bodies as quickly as possible and remain in the singlelegged stance for 6 seconds(Fransz et al., 2018). During the entire test, the participants were instructed to put their hands on the hips, as well as the eyes fixing on a pre-set point on the wall horizontally in front of their orientation at all times during a trial. Should any trial fail to meet the requirements (the opposite foot touch the ground, hands left hips for balance, hopped multiple times for balance after the initial landing, failed to hold the balance in 6 seconds, etc), a re-trial was given after the failed trial. A verbal instruction, a demonstration of SLDJ, and one pre-trial per leg were imparted to the participants after they signed the informed consent. No specific jump height was required.

The ankle trapdoor test was conducted immediately after the SLDJ. A customised trapdoor device was adopted to create the man-made inversion perturbations to the ankle joint to elicit the peroneal muscle reaction. The customised trapdoor device was designed as a hardwooden box, on which a platform with two tilting doors was fixed and hinged around the middle supportive board. A foot stop was installed on each of the 2 doors to standardise the foot width. The tilting angle was set to a maximum of $30^{\circ}$ downward, consistent with previous literature(Chan et al., 2008). The tilting doors were held evenly by a pair of withdrawable trigger blocks sliding through each of the sidewalls of the trapdoor device. Participants were asked to stand on the trapdoor device with one foot on each tilting door closely inside the foot stop, as well as to maintain fully relax with eyes fixed to a point horizontally in the front wall. During the test, randomly, one of the testers rapidly withdrew the trigger block to unlock the tilting door, creating a sudden ankle inversion perturbation (Figure 3). The movement of the trapdoors was recorded by capturing the movement of a pair of reflective markers attached on the foot stop using Vicon MXT T20s (2MP) and T40s (4MP) camera (Sampling rate at $250 \mathrm{HZ}$, Vicon Motion System Ltd, UK).

A pair of surface EMG units (The Trigno Wireless System, Delsys, USA) was attached to the skin surface of the peroneal longus muscle belly to detect peroneal longus muscle reaction (shown in Figure ) before every set of test(Hoch \& McKeon, 2014). The signals of EMG units, force plate, and Vicon motion system were synchronised through Nexus 2 Motion Capture Software (Vicon Motion System Ltd, UK). The temporal interval between the onset of the movement of the trapdoor to the onset of EMG activity was recognised as the peroneal reaction time(Hoch \& McKeon, 2014).

\section{Data processing and analysis}


The sampling rate of EMG was set at $2000 \mathrm{~Hz}$. EMG signal was processed in Excel software (Microsoft Cooperation, USA). All raw EMG data were filtered with a band-pass filter (low pass at $15 \mathrm{~Hz}$ and high pass at $500 \mathrm{~Hz}$ ) and full-wave rectified(Devaprakash et al., 2016; Stegeman \& Hermens, 2007). The baseline EMG signal was defined as the mean magnitude of the EMG signal within 100ms before the withdrawal of the block. The onset of peroneal longus muscle reaction was defined as when the EMG signal suddenly increases and exceeds 3 times the standard deviation of the baseline EMG signal(Silva et al., 2006). Peroneal reaction time was defined by the temporal difference between the onset of the withdrawal and the onset of peroneal muscle reaction. The mean peroneal reaction time was calculated from every 2 trials of each 15-minute-interval for statistical analysis. Since the recording interval of EMG was $0.5 \mathrm{~ms}$, the precision of peroneal reaction time was limited up to the nearest whole number to reduce systematic error.

The sampling rate of the force plate was set at $2000 \mathrm{~Hz}$. GRF data of all directions were processed in Excel software (Microsoft, USA). All raw GRF data were trimmed from the point of impact (defined by the first vertical GRF $>10 \mathrm{~N}$ ) to 6 seconds after the impact. To offset the influence of the body mass, GRF data was related to the mean vertical GRF from the last 2 seconds(Fransz et al., 2018). All GRF data was low-pass filtered at $12 \mathrm{~Hz}$ with bidirectional second-order Butterworth filter. RMS ML 0.4 was calculated by the square root of the mean square of the first $0.4 \mathrm{~s}$ ( 800 frames) of data. Late dynamic MLGRF was obtained by calculating the mean GRF in the mediolateral direction from the third to fifth seconds after impact.

\section{Statistical analysis}

Statistical analysis was performed on the IBM SPSS 24.0 for Mac (International Business Machines Corporation, USA). Repeated measures one-way multivariate analysis of variance (MANOVA) was conducted over the dependent variables overtime points and leg dominance. Should a significant time effect be found, a post hoc Tukey test was then performed to examine whether the dependent variables at each time point significantly differentiated from that at the start (time=0). Should a significant leg dominance effect be found, repeated measures one-way ANOVA was conducted to differentiate the difference between dominant and non-dominant effect. Pearson coefficient correlation analysis was performed to determine if the correlation between the change of the peroneal muscles and the change of landing stability exists. Statistical significance was set at $p<0.05$ level.

\section{RESULTS}

The change of peroneal reaction time, RMS ML 0.4, and late-stage dynamic MLGRF in different time points were shown in Table 1. Repeated measures MANOVA suggested significant time effect (Pillai Trace $=0.953, \mathrm{~F}=5.124, p<0.001$ ) and leg dominance 
difference (Pillai Trace $=0.819, \mathrm{~F}=13.571, p<0.001$ ) over the peroneal reaction time, $\mathrm{RMS}$ ML 0.4 and late dynamic MLGRF. Post hoc Tukey test suggested that the peroneal reaction time for both the dominant and non-dominant leg at 30 minutes, 45 minutes, 60 minutes, 75 minutes, 90 minutes, and 105 minutes of the protocol were significantly longer than that at the start (time $=0$ ), respectively. The test also suggested that the late dynamic MLGRF of the non-dominant leg at 90 minutes of the protocol significantly lower than that at the start. Repeated measures one-way ANOVA showed significant difference effect between dominant and non-dominant leg over RMS ML $0.4\left(\mathrm{~F}_{(1,95)}=42.899, p<0.01\right)$ and late-stage dynamic MLGRF $\left(\mathrm{F}_{(1,95)}=21.585, p<0.01\right)$. No significant correlation except the $45^{\text {th }}$ minute's peroneal reaction time and late dynamic MLGRF was found $\left(\mathrm{r}_{(12)}=-0.686, p=\right.$ 0.014). Time trends of the peroneal muscle reaction results were shown in Figure 4 and time trends of the RMS ML 0.4 and late-stage dynamic MLGRF results were shown in Figure 5.

Table 1. The peroneal reaction time, ground reaction force variables in dominant and nondominant legs at different time points.

\section{DISCUSSION}

The main findings of this study are 1) the peroneal muscle reaction time increased significantly for both legs during the protocol, 2) the RMS ML 0.4 and late dynamic MLGRF did not increase significantly during the protocol, and 3) the dominant legs displayed higher results in the RMS ML 0.4 and late dynamic MLGRF during the progression the protocol.

The results confirmed the first hypothesis that during a 90-minute prolonged football match simulation protocol, the reaction time of the peroneal longus muscle significantly increased in this group of collegiate footballers. The reaction time of peroneal muscles started from 48$58 \mathrm{~ms}$ and increased during the protocol to $60-68 \mathrm{~ms}$ at the end of the protocol. Similar results were reported by Fong et al who recruited amateur female players to perform the LIST protocol, indicating the peroneal reaction time increased significantly in the first 15 minutes during the protocol(D. T. P. Fong et al., 2020). Participants in this study did not show a significant increase in peroneal reaction time until the $45^{\text {th }}$ minute of the protocol. The delay in demonstrating longer peroneal reaction could result from the participants were mainly male and possessed longer training experience. Even though a significant increase was observed, the peroneal reaction time still within the normal range in healthy people, which summarised to be $55-85 \mathrm{~ms}$ based on the previous studies(Eechaute et al., 2009). The timing of delay in the peroneal reaction was indeed consistent with the higher occurrence of LAS in the later phase of both the first and second half of football match(Cloke et al., 2009; Price et al., 2004). It could be speculated that the impaired neuromuscular control could contribute to the high occurrence of LAS in this specific timing, the overall management of mediolateral GRF control, however, seemed not to be impaired during the protocol. 
The results of single-legged dynamic stability defied the second hypothesis. No significant change was shown during the prolonged protocol and even for the non-dominant leg, the late dynamic mediolateral balance even decreased significantly compared to that at the beginning. Previous research identified the higher RMS ML 0.4 and late dynamic MLGRF as two risk factors of LAS, mainly because they represented the inferior management of horizontal GRF perturbation immediately after landing(Fransz et al., 2016, 2018). Thus, the result of this study indicated that the management of mediolateral GRF during single-legged landing perturbation was not impaired during the prolonged football match simulation. Albeit counterintuitive, this discovery was consistent with previous studies on the effect of football training and match on ankle dynamic control and stability. Gioftsidou et al reported that prolonged football training sessions did not impair the stability and balance control in young male football players(Gioftsidou et al., 2006). Pau et al suggested that after one-half of a football match, young football players displayed decreased static balance control but the functional dynamic balance control remained unchanged(Pau et al., 2014). Even though the research done by Greig and McNaught discovered that dynamic balance performance, examined by the change of postural sway, was impaired during a prolonged treadmill protocol(Greig \& McNaughton, 2014), Ashton-Miller et al argued that the postural sway itself did not represent the change of proprioception, rather, it is a measure of motor skill(Ashton-Miller et al., 2001). The steadiness of the unipedal dynamic control throughout football matches and training could due to the long-term training effect(Gioftsidou et al., 2006). In this study, the average training age of participants was 6.3 years and all participants maintained regular football participation before partaking in the experiment. Thus, they might have already adapted to prolonged football participation, training, and match play. The decrease in late dynamic MLGRF of the non-dominant leg at 90 minutes could due to the learning effect of the test(Fransz et al., 2014).

These interesting findings raised the question that whether the higher incidence of LAS in the later stage of the football match was induced by the disruption to the neuromuscular reaction time of the peroneal muscle, or undermined dynamic stability. Peroneal muscles were suggested not the sole protector for the ankle from laterally sprained. All of the peroneal reaction time obtained was longer than the occurrence of LAS which was suggested happened within 40ms from the onset of forceful inversion and/or plantarflexion(Ashton-Miller et al., 1996), indicating the peroneal reaction alone was too late for solely protecting the ankle joint from spraining. Several studies further showed that the eversion torque of the peroneal muscles would not be achieved until 176ms after the inversion perturbation(Lars Konradsen et al., 1997) and the ligamentous complex would have been damaged by this time.

According to the results, it is reasonable to speculate that the body would alter the landing 
strategy during prolonged sport participation. Tamura et al suggested that prolonged biking significantly increased the peak knee flexion angular velocity during single-legged landing to produce higher eccentric torque to attenuate ground reaction force shock(Tamura et al.,

299

300

301

302

303

304

305

306

307

308

309

310

311

312

313

314

315

316

317

318

319

320

321

322

323

324

325

326

327

328

329

330

331

332

333

334 2016). Additionally, Xia et al also reported that prolonged running, shuttle running, and jumping would alter the single-legged landing posture of male collegiate athletes who displayed higher hip and ankle flexion during single-legged after the protocol(Xia et al., 2017). It is worth noticing that in their study, no significant difference in the ground reaction force during landing was found before and after the fatigue. Surprisingly, Eils and Rosenbaum discovered that 6 weeks of sensorimotor training in patients with chronic ankle instability even showed a delaying effect of the peroneal reaction time to synchronise the activity pattern of the peroneal muscles with the tibialis anterior muscle(Eils \& Rosenbaum, 2001). This synchronisation could augment the efficiency of the co-contraction and establish a higher joint stiffness to resist inversion perturbation during landing(Benesch et al., 2000). Under this circumstance, the change of the neuromuscular function could act as an optimisation toward the landing strategy(Eils \& Rosenbaum, 2001; Javed et al., 1999). However, It is yet to know that whether this neuromuscular change resulted from fatigue build-ups during the prolonged sport participation since a previous study confirmed that fatigue itself could affect the proprioception and neuromuscular control(Myers et al., 1999).

\section{Limitations}

Due to low adhesive capacity, the EMG unit was unable to sustain the movements during the protocol and needed to be removed and re-attached before and after every test. The repeated installments of the EMG units could affect the accuracy of the EMG signal acquired. Meanwhile, each test took at least 4 minutes to complete, leaving room for a short recovery to the participants between two blocks of the protocol which seldom did they enjoy during an actual football match. The short recovery could also slightly affect the build-up of fatigue. Additionally, the precision of peroneal reaction time could only be reduced to single digits due to the sampling rate of EMG was limited to $2000 \mathrm{~Hz}$. It is unknown whether a smaller effect would exist using more precisive instruments with a higher sampling rate.

\section{CONCLUSION}

In this study, the first hypothesis was proven but the second hypothesis was rejected. Delayed peroneal reaction time was found in both leg towards the end of the protocol and reduced late dynamic MLGRF was found in the non-dominant leg at 90-minute time points. RMS ML 0.4 for both leg and late dynamic MLGRF in the dominant leg was unchanged throughout the protocol. The results indicated that a more holistic approach should be adopted to study the injury mechanism and injury prevention of LAS, as well as the future study, should focus on finding more sensitive and compelling measurement of single-legged dynamic stability control of the ankle joint. 


\section{REFERENCE:}

337

338

339

340

341

342

343

344

345

346

347

348

349

350

351

352

353

354

355

356

357

358

359

360

361

362

363

364

365

366

367

368

369

370

371

372

373

Anandacoomarasamy, A., \& Barnsley, L. (2005). Long term outcomes of inversion ankle injuries. British Journal of Sports Medicine, 39(3), e14; discussion e14. https://doi.org/10.1136/bjsm.2004.011676

Andersen, T. E., Floerenes, T. W., Arnason, A., \& Bahr, R. (2004). Video Analysis of the Mechanisms for Ankle Injuries in Football. American Journal of Sports Medicine, 32(SUPPL. 1). https://doi.org/10.1177/0363546503262023

Ashton-Miller, J. A., Ottaviani, R. A., Hutchinson, C., \& Wojtys, E. M. (1996). What best protects the inverted weightbearing ankle against further inversion? Evertor muscle strength compares favorably with shoe height, athletic tape, and three orthoses. The American Journal of Sports Medicine, 24(6), 800-809. https://doi.org/10.1177/036354659602400616

Ashton-Miller, J. A., Wojtys, E. M., Huston, L. J., \& Fry-Welch, D. (2001). Can proprioception be trained? Knee Surgery, Sports Traumatology, Arthroscopy, 9(3), 127-127. https://doi.org/10.1007/s001670100214

Benesch, S., Pütz, W., Rosenbaum, D., \& Becker, H. P. (2000). Reliability of peroneal reaction time measurements. Clinical Biomechanics, 15(1), 21-28. https://doi.org/10.1016/S0268-0033(99)00026-1

Chan, Y. Y., Fong, D. T. P., Yung, P. S. H., Fung, K. Y., \& Chan, K. M. (2008). A mechanical supination sprain simulator for studying ankle supination sprain kinematics. Journal of Biomechanics, 41(11), 2571-2574. https://doi.org/10.1016/j.jbiomech.2008.05.034

Cloke, D. J., Spencer, S., Hodson, A., \& Deehan, D. (2009). The epidemiology of ankle injuries occurring in English Football Association academies. British Journal of Sports Medicine, 43(14), 1119-1125. https://doi.org/10.1136/bjsm.2008.052050

Devaprakash, D., Weir, G. J., Dunne, J. J., Alderson, J. A., \& Donnelly, C. J. (2016). The influence of digital filter type, amplitude normalisation method, and co-contraction algorithm on clinically relevant surface electromyography data during clinical movement assessments. Journal of Electromyography and Kinesiology, 31, 126-135.

Dufek, J. S., \& Bates, B. T. (1991). Biomechanical Factors Associated with Injury During Landing in Jump Sports. Sports Medicine, 12(5), 326-337. https://doi.org/10.2165/00007256-199112050-00005

Eechaute, C., Vaes, P., Duquet, W., \& Van Gheluwe, B. (2007). Test-retest reliability of sudden ankle inversion measurements in subjects with healthy ankle joints. Journal of Athletic Training, 42(1), 6065.

Eechaute, C., Vaes, P., Duquet, W., \& Van Gheluwe, B. (2009). Reliability and discriminative validity of sudden ankle inversion measurements in patients with chronic ankle instability. Gait and Posture, 30(1), 82-86. https://doi.org/10.1016/j.gaitpost.2009.03.006

Eils, E., \& Rosenbaum, D. (2001). A multi-station proprioceptive exercise program in patients with ankle instability. Medicine and Science in Sports and Exercise, 33(12), 1991-1998. https://doi.org/10.1097/00005768-200112000-00003

Ekstrand, J. (2013). Keeping your top players on the pitch: The key to football medicine at a professional level. British Journal of Sports Medicine, 47(12), 723-724. https://doi.org/10.1136/bjsports-2013- 
092771

Ekstrand, J., Krutsch, W., Spreco, A., Van Zoest, W., Roberts, C., Meyer, T., \& Bengtsson, H. H. (2019). Time before return to play for the most common injuries in professional football: A 16-year follow-up of the UEFA Elite Club Injury Study. British Journal of Sports Medicine, 54(7), bjsports-2019-100666. https://doi.org/10.1136/bjsports-2019-100666

Ekstrand, J., \& Tropp, H. (1990). The Incidence of Ankle Sprains in Soccer. Foot \& Ankle, 11(1), 41-44. https://doi.org/10.1177/107110079001100108

Fernandes, N., Allison, G. T., \& Hopper, D. (2000). Peroneal latency in normal and injured ankles at varying angles of perturbation. Clinical Orthopaedics and Related Research, 375, 193-201. https://doi.org/10.1097/00003086-200006000-00023

Fong, D. T., Chan, Y.-Y., Mok, K.-M., Yung, P. S., \& Chan, K.-M. (2009). Understanding acute ankle ligamentous sprain injury in sports. BMC Sports Science, Medicine and Rehabilitation, 1(1), 1-14. https://doi.org/10.1186/1758-2555-1-14

Fong, D. T. P., Leung, W. C., Mok, K. M., \& Yung, P. S. H. (2020). Delayed ankle muscle reaction time in female amateur footballers after the first $15 \mathrm{~min}$ of a simulated prolonged football protocol. Journal of Experimental Orthopaedics, 7(1), 1-8. https://doi.org/10.1186/s40634-020-00275-1

Fousekis, K., Tsepis, E., \& Vagenas, G. (2012). Intrinsic risk factors of noncontact ankle sprains in soccer: A prospective study on 100 professional players. American Journal of Sports Medicine, 40(8), 1842-1850. https://doi.org/10.1177/0363546512449602

Fransz, D. P., Huurnink, A., de Boode, V. A., Kingma, I., \& van Dieën, J. H. (2016). Time series of ground reaction forces following a single leg drop jump landing in elite youth soccer players consist of four distinct phases. Gait and Posture, 50, 137-144. https://doi.org/10.1016/j.gaitpost.2016.09.002

Fransz, D. P., Huurnink, A., Kingma, I., de Boode, V. A., Heyligers, I. C., \& van Dieën, J. H. (2018). Performance on a Single-Legged Drop-Jump Landing Test Is Related to Increased Risk of Lateral Ankle Sprains Among Male Elite Soccer Players: A 3-Year Prospective Cohort Study. American Journal of Sports Medicine, 46(14), 3454-3462. https://doi.org/10.1177/0363546518808027

Fransz, D. P., Huurnink, A., Kingma, I., \& van Dieën, J. H. (2014). How does postural stability following a single leg drop jump landing task relate to postural stability during a single leg stance balance task? Journal of Biomechanics, 47(12), 3248-3253. https://doi.org/10.1016/j.jbiomech.2014.06.019

Gioftsidou, A., Malliou, P., Pafis, G., Beneka, A., Godolias, G., \& Maganaris, C. N. (2006). The effects of soccer training and timing of balance training on balance ability. European Journal of Applied Physiology, 96(6), 659-664. https://doi.org/10.1007/s00421-005-0123-3

Greig, M., \& McNaughton, L. (2014). Soccer-specific fatigue decreases reactive postural control with implications for ankle sprain injury. Research in Sports Medicine, 22(4), 368-379. https://doi.org/10.1080/15438627.2014.944300

Hawkins, R. D., Hulse, M. A., Wilkinson, C., Hodson, A., \& Gibson, M. (2001). The association football medical research programme: an audit of injuries in professional football. British Journal of Sports Medicine, 35(1), 43-47. https://doi.org/10.1136/bjsm.35.1.43

Hoch, M. C., \& McKeon, P. O. (2014). Peroneal reaction time after ankle sprain: A systematic review and 
meta-analysis. Medicine and Science in Sports and Exercise, 46(3), 546-556. https://doi.org/10.1249/MSS.0b013e3182a6a93b

415

416

417

418

419

420

421

422

423

424

425

426

427

428

429

430

431

432

433

434

435

436

437

438

439

440

441

442

443

444

445

446

447

448

449

450

451

Javed, A., Walsh, H. P. J., \& Lees, A. (1999). Peroneal reaction time in treated functional instability of the ankle. Foot and Ankle Surgery, 5(3), 159-166. https://doi.org/10.1046/j.1460-9584.1999.00151.x

Konradsen, L., \& Bohsen Ravn, J. (1991). Prolonged peroneal reaction time in ankle instability. International Journal of Sports Medicine, 12(3), 290-292. https://doi.org/10.1055/s-2007-1024683

Konradsen, Lars, Olesen, S., \& Hansen, H. M. (1998). Ankle sensorimotor control and eversion strength after acute ankle inversion injuries. American Journal of Sports Medicine, 26(1), 72-77. https://doi.org/10.1177/03635465980260013001

Konradsen, Lars, Voigt, M., \& Højsgaard, C. (1997). Ankle inversion injuries: The role of the dynamic defense mechanism. American Journal of Sports Medicine, 25(1), 54-58. https://doi.org/10.1177/036354659702500110

Löfvenberg, R., Kärrholm, J., Sundelin, G., \& Ahlgren, O. (1995). Prolonged Reaction Time in Patients with Chronic Lateral Instability of the Ankle. The American Journal of Sports Medicine, 23(4), 414-417. https://doi.org/10.1177/036354659502300407

Myers, J. B., Guskiewicz, K. M., Schneider, R. A., \& Prentice, W. E. (1999). Proprioception and Neuromuscular Control of the Shoulder after Muscle Fatigue. Journal of Athletic Training, 34(4), 362367.

Nicholas, C. W., Nuttall, F. E., \& Williams, C. (2000). The loughborough intermittent shuttle test: A field test that simulates the activity pattern of soccer. Journal of Sports Sciences, 18(2), 97-104. https://doi.org/10.1080/026404100365162

Pau, M., Ibba, G., \& Attene, G. (2014). Fatigue-induced balance impairment in young soccer players. Journal of Athletic Training, 49(4), 454-461. https://doi.org/10.4085/1062-6050-49.2.12

Price, R. J., Hawkins, R. D., Hulse, M. A., \& Hodson, A. (2004). The Football Association medical research programme: An audit of injuries in academy youth football. British Journal of Sports Medicine, 38(4), 466-471. https://doi.org/10.1136/bjsm.2003.005165

Shima, N., Maeda, A., \& Hirohashi, K. (2005). Delayed latency of peroneal reflex to sudden inversion with ankle taping or bracing. International Journal of Sports Medicine, 26(6), 476-480. https://doi.org/10.1055/s-2004-821064

Silva, B. A. R. S., Martinez, F. G., Pacheco, A. M., \& Pacheco, I. (2006). Efeitos da fadiga muscular induzida por exercícios no tempo de reação muscular dos fibulares em indivíduos sadios. Revista Brasileira de Medicina Do Esporte, 12(2), 85-89. https://doi.org/10.1590/s1517-86922006000200006

Stegeman, D., \& Hermens, H. (2007). Standards for surface electromyography: The European project Surface EMG for non-invasive assessment of muscles (SENIAM).

Tamura, A., Akasaka, K., Otsudo, T., Sawada, Y., Okubo, Y., Shiozawa, J., Toda, Y., \& Yamada, K. (2016). Fatigue Alters Landing Shock Attenuation During a Single-Leg Vertical Drop Jump. Orthopaedic Journal of Sports Medicine, 4(1), 1-7. https://doi.org/10.1177/2325967115626412

Thain, P. K., Hughes, G. T. G., \& Mitchell, A. C. S. (2016). The effect of repetitive ankle perturbations on muscle reaction time and muscle activity. Journal of Electromyography and Kinesiology, 30, 184-190. 
https://doi.org/10.1016/j.jelekin.2016.07.004

453

454

455

456

457

458

459

460

461

462

463

464

465

466

467

468

469

470

471

472

473

474

475

476

477

478

479

480

481

482

483

484

485

486

487

488

489

490
Ty Hopkins, J., McLoda, T., \& McCaw, S. (2007). Muscle activation following sudden ankle inversion during standing and walking. European Journal of Applied Physiology, 99(4), 371-378.

https://doi.org/10.1007/s00421-006-0356-9

Waldén, M., Hägglund, M., \& Ekstrand, J. (2013). Time-trends and circumstances surrounding ankle injuries in men's professional football: An 11-year follow-up of the UEFA Champions League injury study. British Journal of Sports Medicine, 47(12), 748-753. https://doi.org/10.1136/bjsports-2013-092223

Witchalls, J. B., Newman, P., Waddington, G., Adams, R., \& Blanch, P. (2013). Functional performance deficits associated with ligamentous instability at the ankle. Journal of Science and Medicine in Sport, 16(2), 89-93. https://doi.org/10.1016/j.jsams.2012.05.018

Xia, R., Zhang, X., Wang, X., Sun, X., \& Fu, W. (2017). Effects of Two Fatigue Protocols on Impact Forces and Lower Extremity Kinematics during Drop Landings: Implications for Noncontact Anterior Cruciate Ligament Injury. Journal of Healthcare Engineering, 2017. https://doi.org/10.1155/2017/5690519

Yeung, M. S., Chan, K. M., So, C. H., \& Yuan, W. Y. (1994). An epidemiological survey on ankle sprain. British Journal of Sports Medicine, 28(2), 112-116. https://doi.org/10.1136/bjsm.28.2.112 
491

492 Table 1. The peroneal reaction time, ground reaction force variables in dominant and non493 dominant legs at different time points.

\begin{tabular}{|c|c|c|c|c|c|c|c|c|c|c|}
\hline \multirow{2}{*}{ Time(min } & \multicolumn{4}{|c|}{$\begin{array}{l}\text { Peroneal reaction time } \\
(\mathrm{ms})\end{array}$} & \multicolumn{3}{|c|}{$\begin{array}{l}\text { RMS ML } 0.4 \\
\text { (\% of body weight) }\end{array}$} & \multicolumn{3}{|c|}{$\begin{array}{l}\text { Late stage dynamic MLGRF } \\
\text { (\% of body weight) }\end{array}$} \\
\hline & Domin & t Sig & $\begin{array}{l}\text { Non- } \\
\text { dominant }\end{array}$ & Sig & Dominant Sig & $\begin{array}{l}\text { Non- } \\
\text { dominant }\end{array}$ & Sig & Dominant Sig & $\begin{array}{l}\text { Non- } \\
\text { dominant }\end{array}$ & Sig \\
\hline 0 & $53 \pm 5$ & - & $54 \pm 3$ & - & $5.64 \pm 1.75-$ & $4.44 \pm 1.60$ & - & $2.00 \pm 1.82-$ & $1.93 \pm 1.67$ & - \\
\hline 15 & $55 \pm 4$ & 0.349 & $56 \pm 3$ & 0.283 & $5.41 \pm 1.291 .000$ & $4.22 \pm 1.89$ & 1.000 & $1.26 \pm 1.020 .789$ & $1.37 \pm 1.20$ & 0.600 \\
\hline 30 & $56 \pm 3$ & 0.299 & $56 \pm 2$ & 0.069 & $5.07 \pm 1.25 \quad 0.987$ & $4.42 \pm 1.89$ & 1.000 & $1.18 \pm 1.040 .984$ & $1.51 \pm 0.74$ & 0.456 \\
\hline 45 & $58 \pm 2$ & $<0.001 * *$ & $59 \pm 3$ & $<0.001 * *$ & $5.99 \pm 2.150 .999$ & $3.84 \pm 1.97$ & 0.994 & $1.14 \pm 0.650 .931$ & $1.49 \pm 0.55$ & 0.394 \\
\hline 60 & $58 \pm 2$ & $0.002 * *$ & $58 \pm 3$ & $0.001 * *$ & $5.54 \pm 2.191 .000$ & $3.99 \pm 2.23$ & 0.999 & $1.33 \pm 0.940 .991$ & $1.62 \pm 0.75$ & 0.716 \\
\hline 75 & $60 \pm 3$ & $<0.001^{* *}$ & $61 \pm 2$ & $<0.001 * *$ & $5.75 \pm 1.49 \quad 1.000$ & $4.43 \pm 1.88$ & 1.000 & $0.91 \pm 0.68 \quad 0.841$ & $1.40 \pm 0.63$ & 0.131 \\
\hline 90 & $61 \pm 3$ & $<0.001 * *$ & $62 \pm 3$ & $<0.001 * *$ & $4.99 \pm 1.050 .974$ & $3.88 \pm 1.37$ & 0.996 & $0.62 \pm 0.45 \quad 0.228$ & $1.02 \pm 0.47$ & $0.019^{*}$ \\
\hline 105 & $64 \pm 4$ & $<0.001^{* *}$ & $64 \pm 3$ & $<0.001 * *$ & $5.25 \pm 1.150 .999$ & $4.54 \pm 2.23$ & 1.000 & $0.95 \pm 0.58 \quad 0.122$ & $0.92 \pm 0.51$ & 0.169 \\
\hline
\end{tabular}

494

RMS ML 0.4: the root mean square of mediolateral ground reaction force in first $0.4 \mathrm{~s}$; Late 495

496

497

498

499

500

501

502

503

504

505

506

507

508

509

510

511

512

513

514

515

516 
518 Legends of figures

519

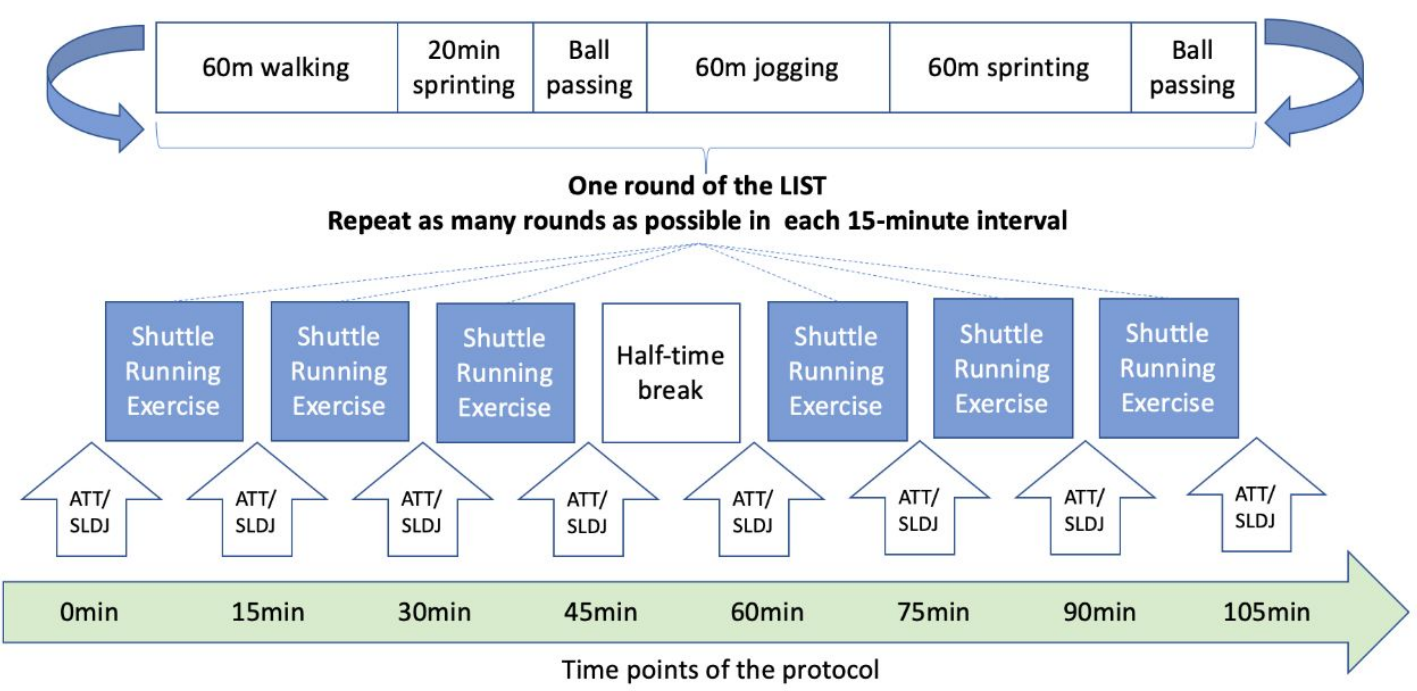

520

521 Figure 1. the LIST protocol and the testing protocol. LIST: Loughborough Intermittent

522 Shuttle Test; ATT: ankle trapdoor test; SLDJ: single-legged drop-jump landing.

523 


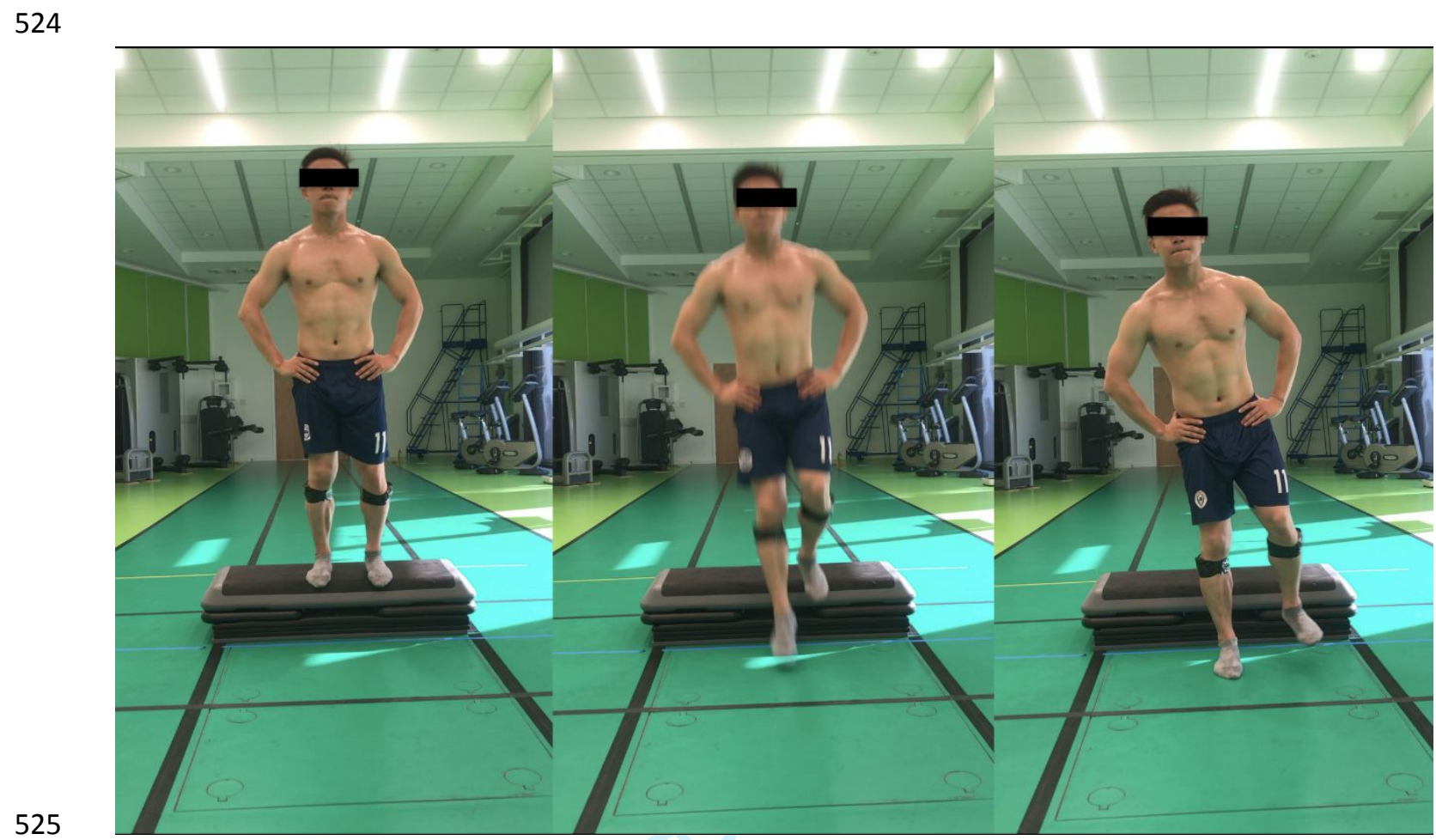

526 Figure 2. Single-legged drop-jump landing (SLDJ) test 


\section{8}

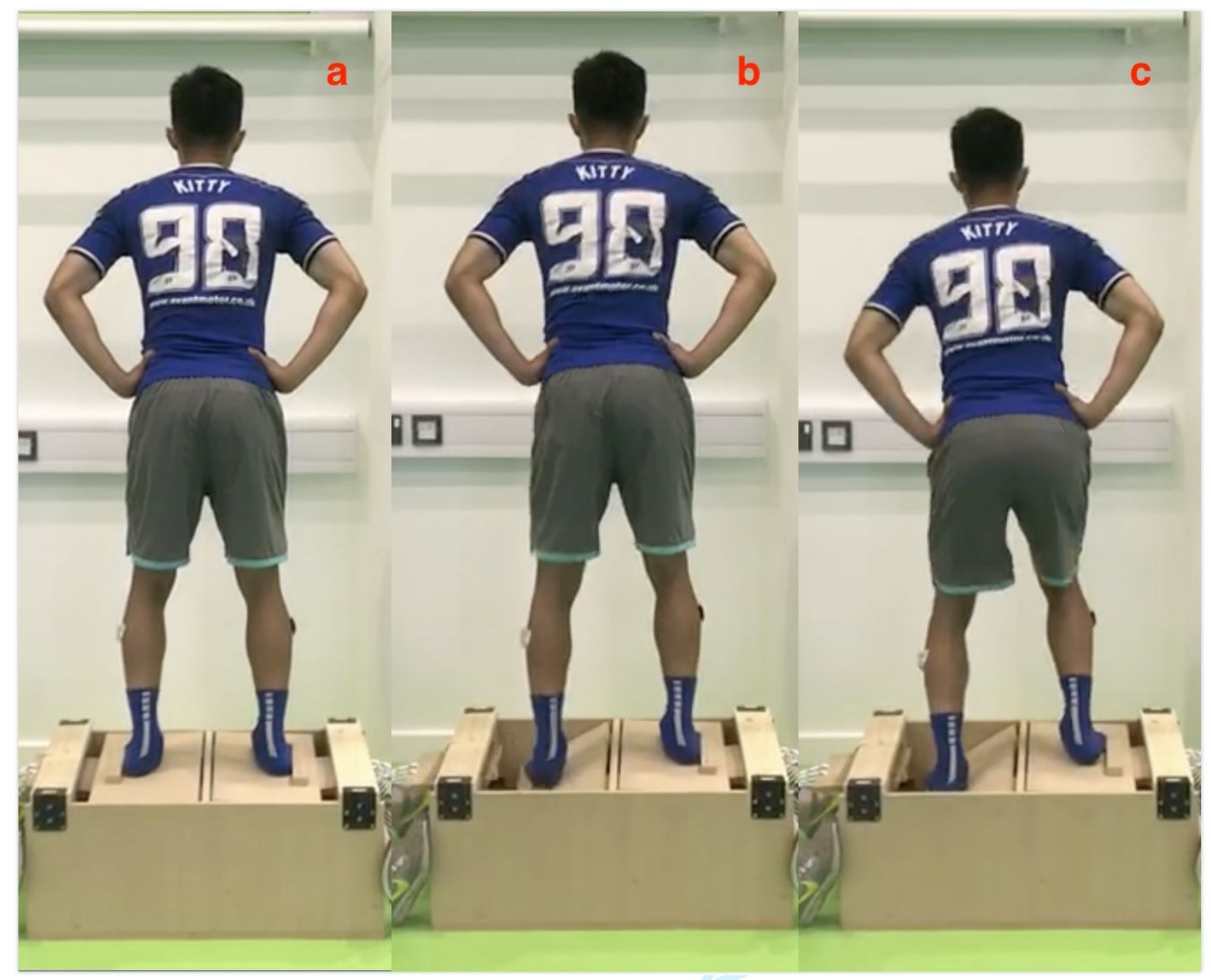

530 Figure 3. Ankle trapdoor test. a. Participant standing on the trapdoor device statically; b. a 531 sudden withdraw from one trigger block and ankle was passively inversed; c. the trapdoor 532 reached the maximum range and the participant regain balance. 
534

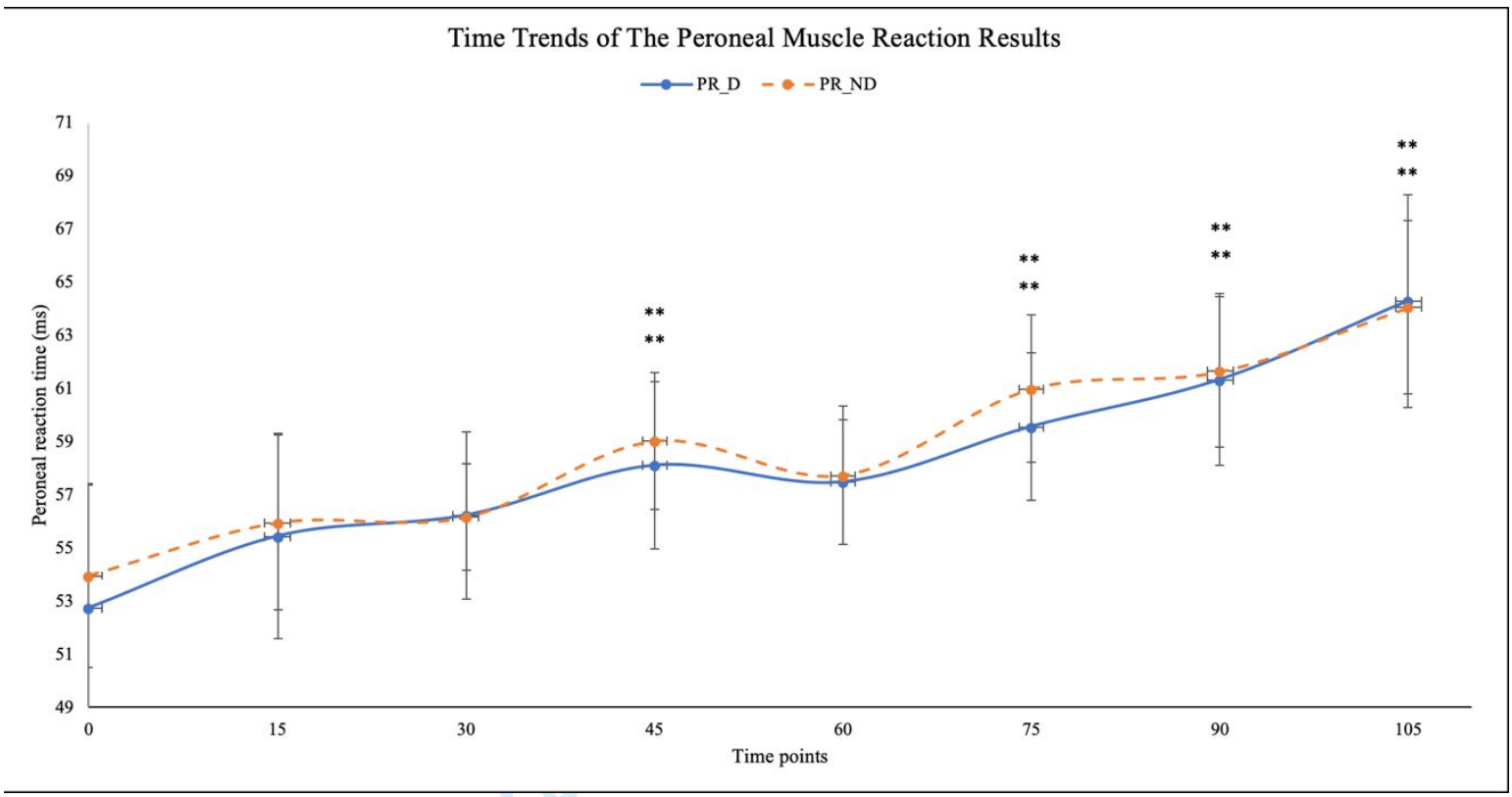

535

536

537

538

539
Figure 4 . The change of the peroneal reaction time at different time point throughout the protocol. $\mathrm{PR}=$ peroneal reaction time; $\mathrm{D}=$ dominant leg; $\mathrm{ND}=$ Non-dominant leg; $*=p<$ $0.05 ; * *=p<0.001$ 
540

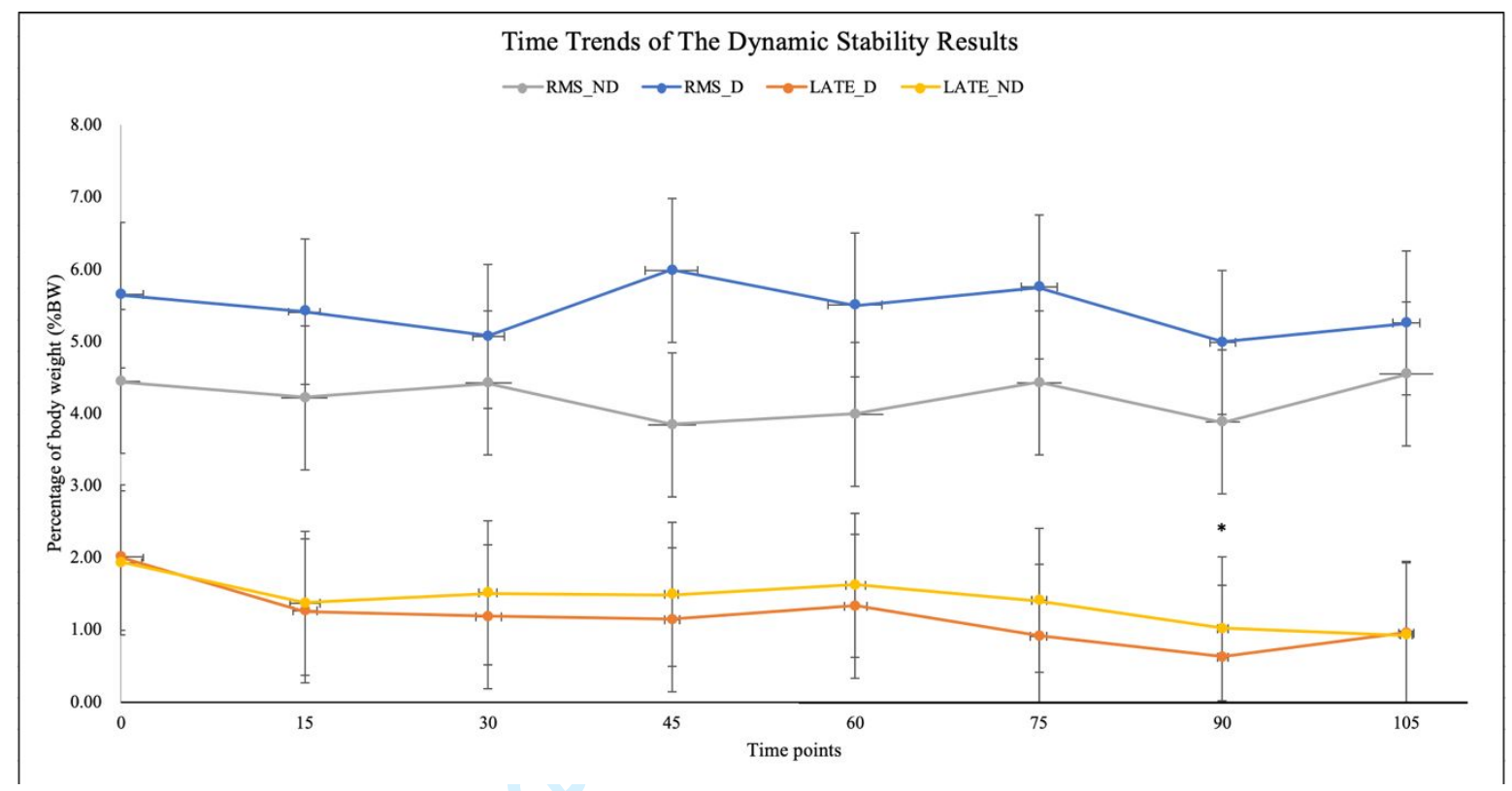
542 Figure 5. The change of RMS ML 0.4 and late stage dynamic MLGRF at different time point
543 throughout the protocol. RMS = RMS ML 0.4; LATE = late stage dynamic MLGRF; D = 544 dominant leg; ND = Non-dominant leg; $*=p<0.05 ; * *=p<0.001$ 